\title{
Inducing flocculation of non-floc-forming Escherichia coli cells
}

\author{
Yoshihiro Ojima, Masayuki Azuma, Masahito Taya
}

\begin{tabular}{|c|l|}
\hline Citation & World Journal of Microbiology and Biotechnology, 34(12); 185 \\
\hline Issue Date & $2018-12$ \\
\hline Type & Journal Article \\
\hline Textversion & author \\
\hline Rights & $\begin{array}{l}\text { This version of the article has been accepted for publication, after peer review (when } \\
\text { applicable) and is subject to Springer Nature's AM terms of use, but is not the Version } \\
\text { of Record and does not reflect post-acceptance improvements, or any corrections. The } \\
\text { Version of Record is available online at: } \underline{\text { https://doi.org/10.1007/s11274-018-2563-z }} \\
\text { Springer Nature's AM terms of use: } \\
\text { https://www.springernature.com/gp/open-research/policies/accepted-manuscript-terms }\end{array}$ \\
\hline DOI & \begin{tabular}{l}
$10.1007 /$ s11274-018-2563-z \\
\hline
\end{tabular} \\
\hline
\end{tabular}

\author{
Self-Archiving by Author(s) \\ Placed on: Osaka City University
}


Mini-review: Inducing flocculation of non-floc-forming Escherichia coli cells

Yoshihiro Ojima $^{\# 1}$, Masayuki Azuma ${ }^{1}$, Masahito Taya ${ }^{2}$

${ }^{1}$ Department of Applied Chemistry and Bioengineering, Graduate School of Engineering, Osaka City University, 3-3-138, Sugimoto, Sumiyoshi-ku, Osaka 558-8585, Japan

${ }^{2}$ Division of Chemical Engineering, Graduate School of Engineering Science, Osaka University, 1-3 Machikaneyama-cho, Toyonaka, Osaka 560-8531, Japan

\#Address correspondence to Yoshihiro Ojima, ojima@bioa.eng.osaka-cu.ac.jp.

Tel: $+81-6-6605-2163$

Keywords: Escherichia coli; microbial flocculation; non-floc-forming bacteria; flocculants 


\section{Abstract}

2 The present article reviews several approaches for inducing flocculation of Escherichia

3 coli cells. The common industrially used bacterium $E$. coli does not naturally have

4 floc-forming ability. However, there are several approaches to induce flocculation of $E$.

5 coli cells. One is induction by flocculants - polyvalent inorganic salts, synthetic

6 polymeric flocculants, or bio-based polymeric materials, including polysaccharide

7 derivatives. Another method is the induction of spontaneous flocculation by changing

8 the phenotypes of E. coli cells; several studies have shown that physical treatment or

9 gene modification can endow E. coli cells with floc-forming ability. Coculturing E. coli

10 with other microbes is another approach to induce E. coli flocculation. These

11 approaches have particular advantages and disadvantages, and remain open to

12 clarification of the flocculation mechanisms and improvement of the induction

13 processes.

14 In this review, several approaches to the induction of E. coli flocculation are

15 summarized and discussed. This review will be a useful guide for the future

16 development of methods for the flocculation of non-floc-forming microorganisms. 


\section{Introduction}

2 Flocculation is an aggregation phenomenon of microbial cells in which the cells form

3 flocs. The floc-forming capabilities of many microorganisms have been studied

4 (Salehizadeh and Shojaosadati 2001). In the 19th century, flocculation of the yeast

5 Levure casseeuese was first reported by Louis Pasteur. Since then, flocculation in 19

6 other diverse microorganisms, including fungi and bacteria, has been confirmed

7 (Nakamura et al. 1976). In the activated sludge used in wastewater treatment and in

8 pure laboratory cultures, the components of flocs typically include polysaccharides,

9 proteins, and polynucleotides. These bacterial flocs are susceptible to hydrolytic

10 enzymes, such as cellulases, proteases, and deoxyribonucleases (Tago and Aida 1977).

11 Although the complete mechanism for microbial flocculation remains unclear,

12 exopolymeric materials play a key role (Salehizadeh and Shojaosadati 2001).

13 Flocculation can also be applied in industrial fermentation. For example, a smart

14 process has been established for high-performance ethanol production from molasses

15 using flocculating Saccharomyces cerevisiae (Morimura et al. 1997). Using flocculating

16 yeast eliminates the costly centrifugation step required for cell recovery during repeated

17 batch ethanol fermentation.

18 However, not all microbial species can form flocs. For example, the commonly used

19 industrial bacterium Escherichia coli does not naturally have floc-forming ability.

20 Therefore, it is necessary to induce the flocculation of such non-floc-forming bacteria.

21 If the objective of flocculation is the removal or inactivation of $E$. coli cells from water,

22 forced flocculation using chemicals or synthetic polymers is effective and inexpensive.

23 If the E. coli flocs are to be used as biocatalysts, environmentally friendly or 
1 spontaneous flocculation is desirable. Therefore, it is desirable to have as many choices

2 as possible of methods to flocculate $E$. coli cells for different purposes.

3 In this review, several approaches to induce flocculation of E. coli cells, a typical 4 non-floc-forming microorganism, are summarized and discussed.

5

6 Approaches for flocculation of $E$. coli cells

Figure 1 summarizes possible approaches for flocculation of non-floc-forming E. coli. These methods can be divided into flocculation of $E$. coli only and flocculation of $E$. 9 coli with other microbes. There are two different approaches for flocculation of E. coli only. The first is using flocculants, which is the standard approach to induce the flocculation of non-floc-forming bacteria. Flocculants are categorized into three typesinorganic chemicals, synthetic polymers, and bio-based polymers. The other approach is by changing the phenotypes or properties of the $E$. coli cells to generate floc-forming ability by means of physical treatment or gene modification. Changing the phenotypes or properties is relatively new and is desirable for the biocatalytic application of E. coli flocs. If using mixed microbial species, the coculture of $E$. coli cells with other microbes that have a floc-forming ability is a strong tool for inducing flocculation. The details of each approach are described below.

\section{Flocculants}

Flocculants are widely used in industrial processes, including wastewater treatment, downstream processing, and food and fermentation processes. As shown in Table 1, the flocculants used can be categorized into three groups; (i) polyvalent inorganic

24 flocculants such as aluminum sulfate; (ii) organic synthetic polymer flocculants, such as 
1 polyethylene imine (PEI) and polyacrylamide derivatives; and (iii) bio-based polymer

2 flocculants, such as chitosan, starch derivatives, and other microbial flocculants

3 (Salehizadeh and Shojaosadati 2001).

4

$5 \quad$ Inorganic chemicals

6 Polyvalent inorganic cations react with water to form hydroxide complexes. These

7 complexes react with phosphorus and suspended particulates to form a relatively 8 insoluble mass, which settles because of many factors, including a reduction of 9 electrical charge. Bacterial cells are colloidal particulates and can be aggregated. In the case of E. coli flocculation, polyvalent inorganic cations, such as aluminum nitrate

11 (Rubin and Hanna 1968) and aluminum sulfate (Bulson et al. 1984) have long been known to be suitable flocculants (Table 1). Recently, compounds of rare earth elements, including lanthanum chloride (Zhang et al. 2010) and cerium nitrate (hen et al. 2010) has been reported to induce flocculation of E. coli cells with high efficiency. However, the high cost of rare earth elements is a problem with this approach. Addition of inorganic compounds is an attractive approach to remove $E$. coli cells from raw water because of the easy handling and low cost.

Synthetic polymers

Organic synthetic polymers are the most typical flocculants used because of their high flocculating efficiency and low cost. In particular, cationic polyelectrolytes can drastically change the degree of flocculation at concentration of ppm. PEI is a typical cationic polyelectrolyte and its mechanism of E. coli flocculation has been well studied

24 (Treweek and Morgan 1977). Based on adsorption experiments and electrophoretic 
1 mobility and refiltration rate measurements, it was concluded that the primary

2 mechanism of flocculation was not polymer bridging, but adsorption coagulation. Small

3 doses of high molecular-weight PEI species contributed to the formation of a charge

4 mosaic on the oppositely charged E. coli cell surface and this resulted in producing

5 rapid flocculation. The adsorbed PEI molecules, not only neutralized the negative

6 surface charge at the adsorption sites, but also caused localized charge reversal because

7 of the presence of excess cationic segments. E. coli flocs induced by PEI have been

8 applied as biocatalysts by Zou et al. (Zou et al. 2018). In this study, recombinant E. coli

9 expressing Acidovorax facilis nitrilase was flocculated with PEI, followed by

10 cross-linking with glutaraldehyde to obtain cross-linked cell aggregates (CLCAs). The

11 CLCAs were investigated as biocatalysts in the regioselective biotransformation of

12 1-cyanocyclohexaneacetonitile into 1-cyanocyclohexaneacetic acid. The results showed

13 that the half-life of the CLCAs was drastically extended compared with that of free

14 cells.

15 Flocculation of $E$. coli cells using other synthetic polymers has been summarized by

16 Barany et al. (Barany and Szepesszentgyorgyi 2004). In this work, nonionic and anionic

17 polymers, including polyethylene oxide, polyvinyl alcohol, carboxylchitin, neutral

18 polyacrylamide, hydrolyzed (anionic) polyacrylamide, and polyacrylic acid showed

19 weak flocculation of $E$. coli cells (less than $20 \%$ removal). In contrast, flexible cationic

20 polyelectrolytes, such as polydiethylaminoethylmethacrylate (polyDEAEMA) and

21 copolymers of polyDEAEMA with vinylpyrrolidone (polyDEAEMA/VP), acrylamide

22 (polyDEAEMA/AA), and acrylic acid (polyDEAEMA/AC), were excellent flocculants

23 of E. coli suspensions; the use of these polymers at concentrations of $15-20 \mu \mathrm{g} / 10^{9}$ cells

24 precipitated $90 \%$ of $E$. coli cells. On the basis of complex measurements of polymer 
1 adsorption and its effect on the electrokinetic potential and degree of aggregation of

2 cells, it was concluded that the aggregation of E. coli cells by polyDEAEMA and

3 copolymers was because of charge neutralization (Barany and Szepesszentgyorgyi

$4 \quad 2004)$.

5

$6 \quad$ Bio-based polymers

7 Traditional flocculants, such as inorganic salts and synthetic polymers, have been

8 proven to provide high flocculation efficiencies in water without large amounts of

9 bacteria. Recently, bio-based flocculants, such as starch, cellulose, chitosan

10 (Salehizadeh and Shojaosadati 2001), and polyglutamic acid (Liu et al. 2018; Liu et al.

$112017 \mathrm{a})$ have attracted increasing attention due to their environmentally friendly property,

12 biodegradability, and widespread availability. In particular, developing novel bio-based

13 polymer flocculants with multi-functionality is important. Traditional flocculants, such

14 as those that are inorganic metal-based as well as synthetic organic polymers, have no evident sterilization activities. Moreover, they themselves carry health risks, because of residual metal ions or the release of noxious polymeric monomers into the target water.

17 General bio-based polymer flocculants have been previously reviewed (Salehizadeh and

18 Shojaosadati 2001; Salehizadeh and Yan 2014). Here, we focus on bio-based polymers

19 targeting flocculation of $E$. coli cells with known compositions (i.e., excluding

20 flocculants based on unclarified bio-based polymers or mixtures). Bio-based polymeric

21 flocculants for $E$. coli cells are summarized in Table 1.

22 Chitosan, the deacetylation product of chitin, appears to be one of the most promising 23 candidates. The unique properties of chitosan mainly arise from the primary amine 24 groups present on the macromolecular backbone. Under acidic conditions, the molecular 
1 chains have a positive charge, suggesting that this biopolymer is quite efficient for

2 flocculating contaminants that have negative surface charges. This fundamental

3 property would clearly provide a benefit in bacterial removal because most bacteria,

4 including E. coli, normally carry negative charges on the outside of their cell walls

5 (Agerkvist et al. 1990). Furthermore, there has been unique research into the fractal

6 structures of flocs formed by chitosan in terms of fractal dimensions (Tang et al. 2001),

7 providing a measurement of how the bacteria in the flocs occupy space. Research has

8 also demonstrated that chitosan shows antibacterial activity. To increase the bactericidal

9 effect, quaternary ammonium salt-grafted carboxymethyl chitosan has been developed

10 for E. coli flocculation (Yang et al. 2014). This polymer has bactericidal action through

11 the breaking of bacterial cell walls by the grafted quaternary ammonium salts. Chitosan

12 has also been used for the flocculation of $E$. coli cells for biocatalytic applications.

13 Flocculation using chitosan within a wide range of molecular weights and degrees of

14 acetylation can achieve a useful immobilization. On the basis of this technique, E. coli cells expressing an omega-transaminase were successfully reused in consecutive batch reactions (Rehn et al. 2013). Despite a very high density of cells in the immobilized preparation, and a fast reaction, diffusion limitation was minimal. Thus, the natural polymer chitosan and its derivatives are highly effective, not only as tools for the removal of bacterial cells from water, but also for the immobilization of bacterial cells for biocatalytic applications.

However, the high cost of chitosan limits its practical applications in water treatment. Starch is an abundant natural resource and much is cheaper than chitosan. Because starch contains large numbers of hydroxyl groups on the saccharide rings, starch can be easily modified chemically for use in various applications by the introduction of 
1 different functional groups onto the backbone. Flocculation of E. coli cells has been

2 reported using carboxymethyl-starch-graft-aminomethylated-polyacrylamide ( $\underline{\text { Huang et }}$

3 al. 2016). Under suitable pH conditions, this flocculant both effectively removed 4 turbidity and disrupted E. coli cells. In recent work, cationized starch-based flocculants

5 (starch-3-chloro-2-hydroxypropyl triethyl ammonium chloride, St-CTA) containing

6 various quaternary ammonium salt groups on the starch backbone have been used for $E$.

7 coli flocculation (Liu et al. 2017b). St-CTA with a high degree of substitution of CTA

8 improved the removal of contaminants due to the strong cationic nature and the charge

9 naturalization flocculation effect. This flocculant showed better antibacterial effects on

10 E. coli cells than on Staphylococcus aureus cells, indicating that the thicker cell walls of

11 the Gram-positive bacterium $S$. aureus are harder to break than the walls of $E$. coli cells.

12 In addition, cationized starch-based flocculants substituted with

13 glycidyltrimethylammonium chloride was also reported (El-Naggar et al. 2018). This

14 flocculant has achieved the same flocculation efficiency of aluminum sulphate. As a

15 new bio-based polymer flocculant, lignin nanoparticles (L-NPs) assembled with gelatin

16 was proposed for the E. coli flocculation (Yin et al. 2018). Positive charge of gelatin is

17 the driving force for flocculation of L-NPs-gelatin complex.

19 Change in cellular phenotypes or properties

20 The addition of flocculants is the most common approach for the flocculation of E. coli cells. However, there are other approaches to induce spontaneous flocculation, including by changing the phenotype or properties of E. coli. Both physical and biological approaches have been reported (Table 2). In the physical approach, an electric field was applied to enteroaggregative E. coli (EAEC) cells. In the biological approach, gene 
1 modification was effective in inducing flocculation of laboratory E. coli strains. Both

2 these approaches can maintain a higher survival rate of E. coli cells inside the floc

3 structure than that in flocs induced by flocculants. Therefore, spontaneous flocculation

4 induced by a phenotype change may be more suitable for application in fermentation

5 processes than using conventional flocculants.

6

$7 \quad$ Physical approaches

EAEC is a diarrheal pathogen defined by a characteristic aggregative adherence to host

9 cells. The EAEC042 strain is known to have important distinguishing properties, such as the positively charged surface protein dispersin and aggregative adherence fimbria

11 (Goochee et al. 1987; Nataro et al. 1985; Sheikh et al. 2002). In normal cases, fimbrial-mediatied EAEC042 adhesion to surfaces leads to biofilm formation. However, Kumar et al. have showed that application of transverse low magnitude alternating current and direct current electric fields in a culture chamber stopped biofilm formation on a glass substrate, and led to flocculation (Kumar et al. 2011). EAEC042 flocs induced by an electric field were more than $200 \mu \mathrm{m}$ in size with a heterogeneous composition. Both the current and magnitude of the electric field were important parameters for controlling the cell viability in those flocs. These findings show promise for the use of electric fields, not only for the manipulation of bacterial flocs, but also for the treatment of medical instruments in preventing aggregative adherence to surfaces.

\section{Biological approaches}

Ojima et al. have demonstrated self-generated flocculation of E. coli cells by overexpressing the native $b c s B$ gene, which encodes a component of transmembrane 
1 cellulose synthase complexes (Ojima et al. 2015). The resulting flocs had a paper-like

2 structure that was stable. Various E. coli laboratory strains including K-12, B, and O

3 formed visible flocs $(>1 \mathrm{~mm})$ by overexpressing the $b c s B$ gene. The presence of green

4 fluorescent protein (GFP)-expressing E. coli cells was confirmed within the floc

5 structure, suggesting that the $E$. coli cells inside the floc structure are likely to be alive.

6 The flocs were sensitive to proteinases, indicating that the main component linking the

7 flocs was proteinous. Both protein analyses and observations of the flocs by

8 transmission electron microscopy indicated the involvement of outer membrane vesicles

9 (OMVs) in the flocculation of E. coli cells. OMVs are extracellular vesicles produced

10 by Gram-negative bacteria and are spherical bilayered proteolipids with a diameter of

$1120-250 \mathrm{~nm}$. OMVs contain outer membrane proteins and lipids, periplasmic proteins,

12 lipopolysaccharides, RNA, and DNA (Lee et al. 2007). Gram-negative bacterial

13 biofilms that have formed either in vivo or in vitro typically contain numerous OMVs

14 (Mashburn-Warren et al. 2008). It has been observed that the $\operatorname{deg} P$-deficient mutant

$15(\triangle \operatorname{deg} P)$ cells spontaneously flocculated without overexpression of $b c s B$ (Ojima et al.

$16 \underline{2015})$. The $\operatorname{deg} P$ gene encodes a periplasmic protease and its deletion strongly enhances

17 OMV production in E. coli cells (Schwechheimer and Kuehn 2013). In contrast,

$18 b c s B$-induced $E$. coli flocculation was greatly suppressed by the deletion of the $\Delta d s b A$

19 or $\Delta d s b B$ gene; these mutants are known to have considerably decreased OMV

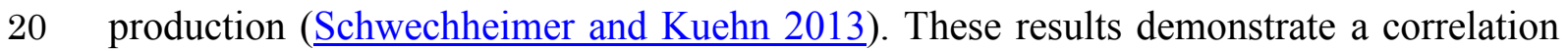

21 between the spontaneous flocculation of E. coli and enhanced OMV production.

22 Compared with forced flocculation, self-generated E. coli flocs have an advantage for

23 application in fermentation processes, because the cells within the flocs maintain the

24 viability and activity required for use as biocatalysts. For example, ethanol-producing $E$. 
1 coli KO11 cells were endowed with floc-forming ability by overexpression of the $b c s B$

2 gene, without adverse effects on ethanol production (Ojima et al. 2016). In this study,

3 the glucose concentration and culture temperature were important parameters for the

4 flocculation of ethanol-producing $E$. coli. Sedimentation tests showed that the $E$. coli

5 flocs completed sedimentation within $15 \mathrm{~min}$ after cessation of shaking, while

6 planktonic cells remained suspended. The advantages of using flocculating $E$. coli

$7 \quad$ KO11 in ethanol production were demonstrated in a repeated batch operation.

8 When examining the flocculation of $b c s B$-overexpressing $E$. coli cells, mass

9 spectrometry analyses indicated that the elongation factor Ts (Tsf) was dominant protein among the floc proteins (Ojima et al. 2015). Tsf is known to promote the release of guanosine diphosphate by forming an intermediate complex with another elongation factor, Tu, which is involved in the elongation cycle of protein biosynthesis (Zhang et al. 1997). A fusion protein consisting of Tsf and GFP was shown to be expressed throughout the whole floc structure, even in the spaces without E. coli cells (Ojima et al. 2018). The amount of Tsf-GFP reached approximately $15 \%(\mathrm{w} / \mathrm{w})$ of the total floc protein, suggesting that the design and synthesis of a fusion protein with Tsf would enable the display of a recombinant target protein on the structure of an E. coli floc. Displaying a recombinant protein on flocs is a promising technique to construct artificial microbial flocs with desired functionalities.

\section{Mixed with other microbes (coculture)}

Table 3 shows reported coculture systems of E. coli with other microbes for inducing flocculation. Flocculation of $S$. cerevisiae has been much investigated because of its importance in the brewing industry (Soares 2011). Flocculation of S. cerevisiae results 
1 from an interaction between a lectin-like protein and mannose residues located on the 2 yeast cell surface. The FLO1 gene, which encodes a cell wall protein, plays an

3 important role in yeast flocculation, which is inhibited by mannose but not by glucose.

4 Interestingly, Peng et al. found flocculation of E. coli cells when they investigated the 5 probiotic effect of yeast cells against diarrhea caused by pathogenic E. coli (Peng et al.

6 1997); E. coli cells flocculated in the supernatant of liquid cultures of an antidiarrheal $S$.

7 cerevisiae strain. This flocculation of $E$. coli cells was induced by a glycoprotein

8 released by the yeast cells.

9 Peng et al. also investigated the coflocculation of $E$. coli cells with a variety of yeast 10 cells (Peng et al. 2001a). The results showed that the E. coli strain JM109 strain 11 coflocculated with Candida utilis G3, Dekkera bruxellensis G1, Hanseniaspora 12 guilliermondii H60, Kloeckera apiculate K315, S. cerevisiae HG, and 13 Schizosaccharomyces pombe G21 strains, even though these yeasts are 14 non-floc-forming strains. In addition, the FLO1 deletion mutant of $S$. cerevisiae also coflocculated with $E$. coli cells, suggesting that coflocculation of $E$. coli and yeast cells is independent of any inherent floc-forming-ability of the yeast cells. S. pombe showed much less coflocculation than the other yeasts. $S$. pombe is known to have galactose-rich cell walls and the glycosylation mutant gms $1 \Delta$ induced a remarkable amount of coflocculation (Peng et al. 2001b). It was concluded that E. coli lectins may have specificity for $\alpha-1-6$ - and $\alpha-1-3$-linked mannose residues of $S$. pombe, but in wild-type $S$. pombe these mannose residues are shielded by galactose residues. Lactobacillus spp. (Ekmekci et al. 2009). Coaggregation of L. acidophilus S1 with E. coli ATCC11229 was observed under both aerobic and anaerobic conditions. The 


\section{Potential applications of different flocculation approaches}

coaggregation of the strains was greater at acidic $\mathrm{pH}$ and decreased after heat treatment. Thus, the coflocculation or coaggregation abilities of probiotic bacteria might enable them to form a barrier that prevents colonization of pathogenic bacteria on host cells.

Table 4 summarizes the advantages and disadvantages of different approaches for inducing $E$. coli flocculation in potential fundamental research and industrial applications. Flocculation of E. coli cells using either inorganic chemicals or synthetic polymers is relatively inexpensive and involves easy handling. These flocculants are suitable for wastewater treatment. However, toxicity toward E. coli cells and detrimental effects on human health are disadvantages for the application of these flocculants in bioproduction, even though several biocatalytic reactions have been proposed using synthetic polymer-induced E. coli flocs. Bio-based polymer flocculants are biodegradable, which gives these flocculants environmentally friendly properties. However, bio-based polymers are not the first choice for wastewater treatment because the cost is relatively high compared with inorganic chemicals or synthetic polymers. A promising application of bio-based polymers is for use in aquaculture feed. Taking advantage of the biodegradability, bio-based polymers can be added to aquaculture ponds to recycle non-utilized proteins and derivative microbial proteins including $E$. coli (Avnimelech 2015). Flocculation of pathogenic E. coli cells by an electric field inhibits the biofilm formation and does not need any added flocculants. However, this method cannot be scaled up easily for bulk reactions. The electrical filed method might be applied for the treatment of medical instruments to prevent biofilm infection. Gene modification induces flocculation, without cost or addition of flocculants, because the 
1 growing cells spontaneously form flocs. However, this approach should only be applied

2 in closed reaction systems due to the legal limitations of handling of genetically 3 modified microorganisms. Repeated batch fermentation is one of the promising 4 applications using the sedimentation property of flocs. In addition, the engineering of 5 flocs by further gene modification is also effective in advancing biocatalytic reactions 6 from the laboratory to an industrial scale. Flocculation by coculture with E. coli has a 7 complex mechanism, which causes difficulty in the handling of the flocculation. In 8 fundamental research, the coculture approach might provide better understanding of 9 microbial interactions through flocculation. The coculture method is also applicable for use in probiotics because the partner microbes remove the pathogenic E. coli cells from the gut in the host animal by the flocculation.

\section{Conclusion}

14 Flocculation of non-floc forming bacteria using added flocculants has been investigated and applied in wastewater treatment. In the case of E. coli flocculation, inorganic-metal-based and synthetic organic polymeric flocculants are effective. However, these traditional flocculants have no evident sterilization activities. Moreover, they themselves carry health risks. Therefore, developing bio-based polymer flocculants with multi-functionality is important. Several types of bio-based polymer flocculants with antibacterial properties efficiently remove $E$. coli cells from water, although the cost is still high. In contrast, flocculation by changing the phenotype of $E$. coli is a novel and economical approach. In particular, such biological approaches can maintain a high survival rate of $E$. coli cells inside the floc structure, and thus are suitable for application in fermentation processes. In particular, flocculation induced by gene 
1 modification is a promising technique to construct artificial microbial flocs with desired

2 functions. Coflocculation of $E$. coli and other microbes is a complex phenomenon;

3 coflocculation with probiotic bacteria might enable the formation of a barrier that

4 prevents colonization of pathogenic E. coli on host cells.

5

6 Acknowledgments

7 The authors acknowledge financial support from a Grant-in-Aid for Young Scientists

8 (B) (No. 17K14869) from the Ministry of Education, Culture, Sports, Science and

9 Technology of Japan, and a Chemical Innovation Encouragement Prize from the Japan

10 Association for Chemical Innovation. A draft of this manuscript was proofed by James

11 Allen, D. Phil, from Edanz Group (www.edanzediting.com/ac).

12

\section{Conflict of interest}

14 The authors declare that they have no conflict of interest.

\section{References}

Agerkvist I, Eriksson L, Enfors SO (1990) Selective flocculation with chitosan in

Barany S, Szepesszentgyorgyi A (2004) Flocculation of cellular suspensions by polyelectrolytes. Adv Colloid Interface Sci 111(1-2):117-129

24 Bulson PC, Johnstone DL, Gibbons HL, Funk WH (1984) Removal and inactivation of 
bacteria during alum treatment of a lake. Appl Environ Microbiol 48(2):425-430

Chen A, Shi Q, Feng J, Ouyang Y, Chen Y, Tan S (2010) Dissociation of outer membrane for Escherichia coli cell caused by cerium nitrate. J Rare Earth 28(2):312-315

Ekmekci H, Aslim B, Ozturk S (2009) Characterization of vaginal lactobacilli coaggregation ability with Escherichia coli. Microbiol Immunol 53(2):59-65

El-Naggar ME, Samhan FA, Salama AAA, Hamdy RM, Ali GH (2018) Cationic starch: Safe and economic harvesting flocculant for microalgal biomass and inhibiting $E$. coli growth. Int J Biol Macromol 116:1296-1303

Goochee CF, Hatch RT, Cadman TW (1987) Some observations on the role of type 1 fimbriae in Escherichia coli autoflocculation. Biotechnol Bioeng 29(8):1024-1034

Huang M, Wang Y, Cai J, Bai J, Yang H, Li A (2016) Preparation of dual-function starch-based flocculants for the simultaneous removal of turbidity and inhibition of Escherichia coli in water. Water Res 98:128-137

Kumar A, Mortensen P, Mukherjee P, Retterer T, Dokytcz M (2011) Electric field induced bacterial flocculation of enteroaggregative Escherichia coli 042. Appl Phys Lett 98(25):253701

Lee EY, Bang JY, Park GW, Choi DS, Kang JS, Kim HJ, Park KS, Lee JO, Kim YK, Kwon KH, Kim KP, Gho YS (2007) Global proteomic profiling of native outer membrane vesicles derived from Escherichia coli. Proteomics 7(17):3143-53

Liu T, Nobeshima H, Ojima Y, Azuma M (2018) A new method to purify poly- $\boldsymbol{\gamma}$-glutamic acid using gemini quaternary ammonium salts and characterization of its ionic complex. J Chem Eng Jpn 51(5):431-437

Liu T, Yamashita Y, Fukumoto T, Tachibana T, Azuma M (2017a) Flocculation of real 
sewage sludge using polyglutamic acid produced by Bacillus sp. isolated from soil. J Chem Eng Jpn 50(3):201-206

Liu Z, Huang M, Li A, Yang H (2017b) Flocculation and antimicrobial properties of a cationized starch. Water Res 119:57-66

Mashburn-Warren L, McLean RJ, Whiteley M (2008) Gram-negative outer membrane vesicles: beyond the cell surface. Geobiology 6(3):214-9

Morimura S, Ling ZY, Kida K (1997) Ethanol production by repeated-batch fermentation at high temperature in a molasses medium containing a high concentration of total sugar by a thermotolerant flocculating yeast with improved salt-tolerance. J Ferment Bioeng 83(3):271-274

Nakamura J, Miyashiro S, Hirose Y (1976) Purification and chemical analysis of microbial cell flocculant produced by Aspergillus sojae AJ 7002. Agr Biol Chem 40(3):619-624

Nataro JP, Baldini MM, Kaper JB, Black RE, Bravo N, Levine MM (1985) Detection of an adherence factor of enteropathogenic Escherichia coli with a DNA Probe. J Infect Dis 152(3):560-565

Ojima Y, Nguyen MH, Yajima R, Taya M (2015) Flocculation of Escherichia coli cells in association with enhanced production of outer membrane vesicles. Appl Environ Microbiol 81(17):5900-5906

Ojima Y, Nunogami S, Azuma M, Taya M (2018) Displaying a recombinant protein on flocs self-produced by Escherichia coli through fused expression with elongation factor Ts. Enzyme Microbial Technol 108:21-25

Ojima Y, Takeda S, Taya M (2016) Floc formation of ethnaol producing Escherichia coli KO11 cells and its application to repeated batch operation. J Chem Eng Jpn 
49(8):793-798

Peng X, Iserentant D, Verachtert H (1997) Effect of cultivation conditions on the yeast-induced flocculation of Escherichia coli. Food Technol Biotechnol 35(4):243-247

Peng X, Sun J, Iserentant D, Michiels C, Verachtert H (2001a) Flocculation and coflocculation of bacteria by yeasts. Appl Microbiol Biotechnol 55(6):777-781

Peng X, Sun J, Michiels C, Iserentant D, Verachtert H (2001b) Coflocculation of Escherichia coli and Schizosaccharomyces pombe. Appl Microbiol Biotechnol $57(1-2): 175-181$

Rehn G, Grey C, Branneby C, Adlercreutz P (2013) Chitosan flocculation: an effective method for immobilization of E. coli for biocatalytic processes. J Biotechnol 165(2):138-144

Rubin AJ, Hanna GP (1968) Coagulation of the bacterium Escherichia coli by aluminum nitrate. Environ Sci Technol 2(5):358-362

Salehizadeh H, Shojaosadati SA (2001) Extracellular biopolymeric flocculants. Recent trends and biotechnological importance. Biotechnol Adv 19(5):371-385

Salehizadeh H, Yan N (2014) Recent advances in extracellular biopolymer flocculants. Biotechnol Adv 32(8):1506-1522

Schwechheimer C, Kuehn MJ (2013) Synthetic effect between envelope stress and lack of outer membrane vesicle production in Escherichia coli. J Bacteriol 195(18):4161-4173

Sheikh J, Czeczulin JR, Harrington S, Hicks S, Henderson IR, Le Bouguenec C, Gounon P, Phillips A, Nataro JP (2002) A novel dispersin protein in enteroaggregative Escherichia coli. J Clin Invest 110(9):1329-1337 
1 Soares EV (2011) Flocculation in Saccharomyces cerevisiae: a review. J Appl Microbiol

2

$$
110(1): 1-18
$$

Tago Y, Aida K (1977) Exocellular mucopolysaccharide closely related to bacterial floc formation. Appl Environ Microbiol 34(3):308-314

Tang S, Ma Y, Sebastine IM (2001) The fractal nature of Escherichia coli biological flocs. Colloids Surf B 20(3):211-218

Treweek GP, Morgan JJ (1977) The mechanism of E. coli aggregation by polyethyleneimine. J Colloid Interface Sci 60(2):258-273

Yang Z, Degorce-Dumas JR, Yang H, Guibal E, Li A, Cheng R (2014) Flocculation of Escherichia coli using a quaternary ammonium salt grafted carboxymethyl chitosan flocculant. Environ Sci Technol 48(12):6867-6873

Yin H, Liu L, Wang X, Wang T, Zhou Y, Liu B, Shan Y, Wang L, Lü X (2018) A novel flocculant prepared by lignin nanoparticles-gelatin complex from switchgrass for the capture of Staphylococcus aureus and Escherichia coli. Colloids Surf A Physicochem Eng Asp 545:51-59

Zhang Y, Riley LK, Lin M, Hu Z (2010) Lanthanum-based concentration and microrespirometric detection of microbes in water. Water Res 44(11):3385-3392

Zhang Y, Sun V, Spremulli LL (1997) Role of domains in Escherichia coli and mammalian mitochondrial elongation factor Ts in the interaction with elongation factor Tu. J Biol Chem 272(35):21956-21963

Zou S-P, Huang J-W, Xue Y-P, Zheng Y-G (2018) Highly efficient production of 1-cyanocyclohexaneacetic acid by cross-linked cell aggregates (CLCAs) of recombinant E. coli harboring nitrilase gene. Process Biochem 65:93-99 


\section{FIGURE LEGEND}

3 Fig. 1 Categories of approaches for inducing flocculation of non-floc-forming $E$. coli cells.

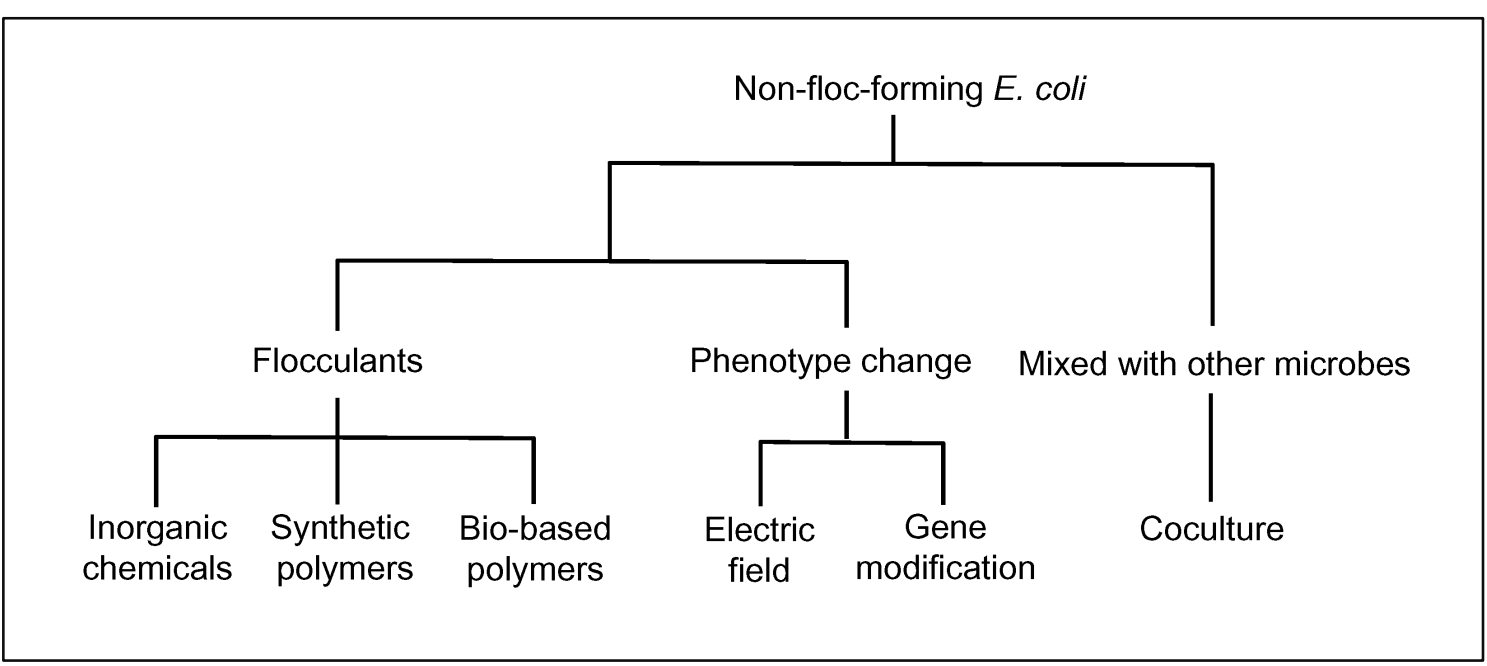


Table 1 Materials for flocculation of E. coli

\begin{tabular}{|c|c|c|}
\hline Flocculants & Characteristics & References \\
\hline \multicolumn{3}{|l|}{ Inorganic chemicals } \\
\hline Aluminum sulfate & Reduction of electrical charge & Bulson et al. 1984 \\
\hline Aluminum nitrate & Reduction of electrical charge & Rubin and Hanna 1968 \\
\hline Lanthanum chloride & Reduction of electrical charge & Zhang et al. 2010 \\
\hline Cerium nitrate & Reduction of electrical charge & Chen et al. 2010 \\
\hline \multicolumn{3}{|l|}{ Synthetic polymers } \\
\hline Polyethyleneimine (PEI) & Positive charge & Treweek and Morgan 1977 \\
\hline Polyethyleneimine (PEI) & Biocatalytic application & Zou et al. 2018 \\
\hline $\begin{array}{l}\text { polydiethylaminoethylmetacrylate (polyDEAEMA) } \\
\text { and its copolymers }\end{array}$ & Charge neutralization & $\begin{array}{l}\text { Barany and } \\
\text { Szepesszentgyorgyi } 2004\end{array}$ \\
\hline \multicolumn{3}{|l|}{ Bio-based polymers } \\
\hline Chitosan & Positive charge & Agerkvist et al. 1990 \\
\hline Chitosan & Characterization of fractal structure & Tang et al. 2001 \\
\hline $\begin{array}{l}\text { Quaternary ammoniumsalt grafted carboxymethyl } \\
\text { chitosan (CMC-g-PDMC) }\end{array}$ & $\begin{array}{l}\text { Increased charge and bridging with } \\
\text { bactericide }\end{array}$ & Yang et al. 2014 \\
\hline Chitosan & Biocatalytic application & Rehn et al. 2013 \\
\hline $\begin{array}{l}\text { Carboxymethyl starch-grafted } \\
\text { aminomethylated-polyacrylamide (CMS-g-APAM) }\end{array}$ & Positive charge with bactericide & Huang et al. 2016 \\
\hline $\begin{array}{l}\text { Starch-3-chloro-2-hydroxypropyl triethyl ammonium } \\
\text { chloride (St-CTA) }\end{array}$ & Positive charge with bactericide & Liu et al. $2017 \mathrm{~b}$ \\
\hline $\begin{array}{l}\text { Cationized starch with glycidyltrimethylammonium } \\
\text { chloride (GTAC) }\end{array}$ & Positive charge with bactericide & El-Naggar et al. 2018 \\
\hline Lignin nanoparticles assembled with gelatin & Positive charge & Yin et al. 2018 \\
\hline
\end{tabular}


Table 2 Modification of cellular phenotypes or properties of $E$. coli for flocculation

\begin{tabular}{lcc}
\hline \multicolumn{1}{c}{ Approaches } & Mechanisms & References \\
\hline $\begin{array}{l}\text { Type1 fimbriae-positive } \\
\text { cell at low } \mathrm{pH}\end{array}$ & Fimbriae-to-fimbriae adhesion & Goochee et al. 1987 \\
$\begin{array}{l}\text { Electric field } \\
\text { Overexpression of } \\
b c s B \text { gene }\end{array}$ & Fimbriae-to-fimbriae adhesion & Kumar et al. 2011 \\
Deletion of $\operatorname{deg} P$ gene & Proteinous component & Ojima et al. 2015 \\
\hline
\end{tabular}


Table 3 Cocultures of $E$. coli with other microbes for flocculation

\begin{tabular}{|c|c|c|}
\hline Strains & Phenomena & References \\
\hline $\begin{array}{l}\text { S. cerevisiae } \\
\text { (antidiarrhea strain) }\end{array}$ & $\begin{array}{l}\text { flocculation in the } \\
\text { culture supernatant }\end{array}$ & Peng et al. 1997 \\
\hline C. utilis $\mathrm{G} 3$ & coflocculation & Peng et al. 2001a \\
\hline D. bruxellensis G1 & coflocculation & Peng et al. 2001a \\
\hline H. guilliermondii $\mathrm{H} 60$ & coflocculation & Peng et al. 2001a \\
\hline K. apiculate K315 & coflocculation & Peng et al. 2001a \\
\hline S. cerevisiae $\mathrm{HG}$ & coflocculation & Peng et al. 2001a \\
\hline S. pombe & coflocculation & Peng et al. 2001b \\
\hline $\begin{array}{l}\text { Lactobacillus spp. } \\
\text { (isolated from the lateral vaginal walls) }\end{array}$ & coaggregation & Ekmekci et al. 2009 \\
\hline
\end{tabular}


Table 4 Advantages and disadvantages of different approaches for inducing E. coli flocculation in potential fundamental research and industrial applications

\begin{tabular}{|c|c|c|c|c|}
\hline Approaches & Advantages & Disadvantages & Fundamental research & Industrial application \\
\hline Inorganic chemicals & $\begin{array}{l}\text { Low cost/ } \\
\text { Easy handling }\end{array}$ & Toxicity & - & Wastewater treatment \\
\hline Synthetic polymers & Easy handling & Toxicity & - & Wastewater treatment \\
\hline Bio-based polymers & $\begin{array}{l}\text { Environmentally } \\
\text { friendly }\end{array}$ & High cost & - & $\begin{array}{c}\text { Aquaculture feed/ } \\
\text { Biocatalytic reactions }\end{array}$ \\
\hline Electrical field & $\begin{array}{l}\text { Easy handling/ } \\
\text { Without flocculants }\end{array}$ & Small scale & - & $\begin{array}{l}\text { Treatment of medical } \\
\text { instruments }\end{array}$ \\
\hline Gene modification & $\begin{array}{l}\text { Low cost/ } \\
\text { Without flocculants }\end{array}$ & $\begin{array}{l}\text { Legal limitations of } \\
\text { handling }\end{array}$ & $\begin{array}{l}\text { Construction of } \\
\text { engineered flocs }\end{array}$ & $\begin{array}{c}\text { Repeated batch fermentation/ } \\
\text { Biocatalytic reactions }\end{array}$ \\
\hline Cocultures & $\begin{array}{l}\text { Low cost/ } \\
\text { Without flocculants }\end{array}$ & Difficult handling & $\begin{array}{c}\text { Understanding of } \\
\text { microbial interactions }\end{array}$ & $\begin{array}{c}\text { Wastewater treatment/ } \\
\text { Probiotics }\end{array}$ \\
\hline
\end{tabular}

